might contribute not only to fire ant control but also to an understanding of parasitism's role in structuring natural communities.

M. R. Orr*

S. H. Seike ${ }^{\dagger}$

W. W. Benson ${ }^{\dagger}$

L. E. Gilbert*

*Brackenridge Field Laboratory and

Department of Zoology,

The University of Texas at Austin,

Austin, Texas 78712, USA

† LIIP, Departamento de Zoologia,

Universidade Estadual de Campinas,

Caixa Postal 6109, 13083-970 Campinas,

São Paulo, Brazil

\section{Leukaemia and wartime evacuees}

SIR - A high degree of mixing of urban and rural groups of people is associated with significant increases of childhood leukaemia, a phenomenon that is consistent with an infective process being responsible ${ }^{1-7}$.

The evacuation by the government of large numbers of urban children during the Second World War is such a situation, which we have recently studied in relation to childhood leukaemia ${ }^{8}$.

The 476 rural districts of England and Wales were grouped into three categories with similar numbers of local children but with contrasting proportions of government evacuees in 1941. In the 'high' category, leukaemia mortality in the years 1945-49 (the earliest period for which data are available) showed a $47 \%$ excess relative to the 'low' category, with a significant trend across the categories. Doubt has been cast in Scientific Correspondence $^{9}$ on this infection-based hypothesis because mortality rates from childhood leukaemia in England and Wales showed no sudden increase during or just after the war. National mortality rates are inevitably rather insensitive to changes in rural areas, given the small proportion of the country's children who live there (and in fact the 'high' rural category held only $6.3 \%$ ). Wartime evacuation therefore does not represent an exception in this context.

\section{J. Kinlen}

S. M. John

CRC Cancer Epidemiology Research Group, University of Oxford, Radcliffe Infirmary, OXford OX2 $6 \mathrm{HE}$, UK

1. Kinlen, L. J. Lancet Ii, 1323-1327 (1988).

2. Kinlen L J Lancet 336, 577-582 (1990)

3. Kinlen, L. \& Hudson C. Br. med. 303, 1357-1362 (1991).

. Kinlen, L. J., Hudson, C \& Stiller, C. Br. J. Cancer 64 549-554 (1991).

5. Kinlen, L. J. et al. Br. med. J. 306, 743-748 (1993)

6. Langford, I. Soc. Sci. med. 33, $435-440$ (1991).

7. Kinlen, L. J. Br. J. Cancer 71 1-5 (1995).

8. Kinlen, L. J. \& John, S. M. Br. Med. J. 309, 1197-1202 (1994).

9. Wolff, S. P. Nature 349, 23 (1991).

\section{Organic carbon in sediments}

SIR - Hartgers et al. ${ }^{1}$ convincingly demonstrate the presence of derivatives of isorenieratene and a novel $\mathrm{C}_{40}$ diaromatic carotenoid in the aromatic hydrocarbon fractions of Duvernay Formation sourced crude oils, and in chemical and pyrolytic degradation products of associated crude oil asphaltenes and source rock kerogens. From this they argue that there are contributions from green sulphur bacterial components in the sedimentary organic matter in the Palaeozoic sediments of Western Canada and elsewhere. The authors further suggest that because these biomarker compounds - indicative of a specific group of photosynthetic bacteria - show carbon isotope signatures significantly different from the bulk total organic carbon (TOC), these organisms have not contributed significantly to the carbon preserved in the sediments from Western Canada and the Williston basins.

We agree with this conclusion, as well as with the argument of Hartgers et al. ${ }^{1}$ that substantial biases occur in the quantitative interpretation of biological marker data in terms of source biomass contribution to bulk TOC. This bias is likely to occur in quantitative assessments of biological marker contributions from bound fractions, particularly when relative concentrations of components in gas chromatograms are used.

Nevertheless, we are cautious about the overall general conclusion of the paper ${ }^{1}$. The inference that bacterial biomass (implying all bacteria) is a minor component of sedimentary organic matter has not yet been tested and, indeed, remains one of the most important questions in biogeochemistry. Hartgers et al. ${ }^{1}$ suggest that selective preservation of specific biomarker compounds has led to overstating their significance as indicators of sources of sedimentary organic matter. Although undoubtedly true in this specific case, and perhaps more widely ${ }^{2}$, this suggestion does obscure the wider, more significant, issue that microorganisms other than phototoautotrophs are likely to contribute considerable amounts of organic carbon to sedimentary basins. The arguments for this are twofold: (1) the work of Parkes et al. ${ }^{3}$ shows that there is significant bacterial production resulting from growth of bacteria on organic matter deposited in sediments from the overlying water column; and (2) in present-day marine basins, typically $18-30 \%$ of photosynthetically fixed carbon contributes to the growth of heterotrophic bacteria ${ }^{4}$ and in some highly eutrophic environments up to $80 \%$ of photosynthetically fixed carbon is converted to bacterial biomass ${ }^{5}$. This may be of consequence in the light of pre- liminary evidence for the occurrence of resistant macromolecular components in some bacteria ${ }^{6}$.

The contribution of bacterial biomass to the global carbon budget is of fundamental importance to the biogeochemistry of our planet, having consequences not only for the biogeochemical cycling of oxygen and carbon, but also for palaeoenvironmental reconstructions and the formation of oilprone sediments. In combination, the arguments of Parkes et al. ${ }^{3}$ and of Ducklow and Carlson ${ }^{4}$ indicate that non-photosynthetically produced bacterial biomass must be significant in the formation of sedimentary organic matter in general. At the other end of the spectrum, the TOC in sediments from the extreme environments of microbial mats may derive mainly from bacterial sources ${ }^{7}$ including photosynthetic bacterial input. In such situations ${ }^{8}$, bacterial markers and the bulk TOC have similar, very heavy, carbon isotope signatures. Thus, Gaia notwithstanding, the jury is still out, and the general conclusion of Hartgers et al. that "bacterial biomass may commonly represent only a minor component of total $\mathrm{C}_{\text {org }}$ in carbonaceous rocks" may be premature.

Ian Head, Paul Farrimond, Steve Larter

Newcastle Research Group in Fossil

Fuels and Environmental

Geochemistry,

University of Newcastle upon Tyne

Newcastle upon Tyne NE1 7RU, UK

HARTGERS $E T$ AL. REPLY - Head et al. argue that heterotrophic bacterial biomass production in both the water column $n^{4,5}$ and surface sediments ${ }^{3}$ is important. We agree. However, this by no means implies that bacterial carbon will be ultimately preserved.

Organic matter preserved in sediments represents only a very small portion of organic carbon of biomass, the recalcitrant portion such as algaenans ${ }^{9}$ and cutans ${ }^{10}$. In fact, its selective preservation is due to the processes mentioned by Head et al. operating in the water column and sediments up to 800 metres below sea floor. Parkes et al. ${ }^{3}$ convincingly demonstrated that the uncharacterized portion of the TOC (non-protein, non-carbohydrate, non-lipid) increases to $80 \%$ at $10 \mathrm{~m}$ depth in sediments of the Peru Margin. The authors suggested that this unsaponifiable, macromolecular material represents 'bacterial necromass'. The material thus far resisted chemical characterization.

In a more recent paper, Parkes and co-workers ${ }^{11}$ provide evidence that "bacterial necromass" is a good substrate for other bacteria. This implies, in our view, that bacterial carbon can be recycled as efficiently as the primary photosynthate and is, thus, ultimately completely remineralized if no recalcitrant carbon is present. For example, Saddler and Ward- 